\title{
DEVELOPMENT OF MOTION SYSTEMS FOR FLIGHT SIMULATORS
}

\author{
Rafał LEWKOWICZ', Grzegorz KOWALECZKO² \\ 1 Department of Simulator Studies and Aeromedical Training, Military Institute of Aviation Medicine, \\ Warsaw, Poland \\ 2 Department of Aviation, Military University of Aviation, Dęblin, Poland
}

Source of support: Statutory activity of WIML.

Author's address: R. Lewkowicz, Military Institute of Aviation Medicine, Krasińskiego 54/56 Street, 01-755 Warsaw, Poland, e-mail: rlewkowicz@wiml.waw.pl

Abstract: Despite the ongoing disputes about the need to use motion systems in flight simulators, the development of this component of simulators has been ongoing since the beginning of aviation. The aim of the article is to discuss the importance of the motion system in the simulation of motion stimuli affecting the aircraft pilot. Selected motion systems of flight simulators and reasons for using these systems are described. The benefits of the use of motion stimuli in flight simulators are discussed and possible directions of development of the motion system are presented.

Keywords: flight simulator, motion system, motion stimuli, motion cueing fidelity 


\section{INTRODUCTION}

Flight simulators were the first devices, whose purpose was not to imitate the appearance of a particular aircraft, but to imitate its dynamic properties [41]. For this reason, one of the most important components of flight simulators was and still is the motion system, the task of which is to imitate motion stimuli occurring in real flight.

Despite the ongoing disputes about the need to use motion systems in flight simulators, the development of this component of simulators has been ongoing since the beginning of aviation. The aim of the article is to discuss the importance of the motion system in the simulation of motion stimuli affecting the aircraft pilot.

\section{FIRST MOTION SYSTEMS}

Already at the time of construction of the first flight simulators, the motion system was an important part of them. One of the first devices simulating the flight conditions was Model B "Flyer" of the Wright Brothers' aircraft without the tail part and engine [29]. The simulator was equipped with a cam driven by an electric motor, which enabled continuous changes in its roll. This motion was a key stimulus during training. The student could keep the wings horizontal by tilting the rudder levers. After a few hours of such training, appropriate habits appeared in the form of movements to correct imbalances during a simulated flight. Mastering this art qualified the student to fly a real Flyer-B aircraft.

In 1909, the Antoinette company, making aircraft and offering pilotage training, developed the Antoinette Trainer training device [15]. It consisted of two half barrels, mounted one on top of the other (fig. 1), which made it possible to simulate the roll and pitch of an aircraft. Changes to these angles were made manually by the staff operating the simulator, and the pilot's task was to keep the horizontal reference beam parallel to the horizon plane using the rudders (two wheels). The pilot's function in this simulator can therefore be compared to that of the most important on-board instrument, the attitude horizon (artificial horizon) indicator. The simulator was used to teach pilots to react correctly to stimuli they experience in flight in the form of typical aircraft pitch and roll movements. In hindsight, it turned out that this representation of the cabin's positions and the acquired ability to maintain reference to the natural horizon was incorrect. However, most of the aviation pioneers were not aware of this fact, as it was only at that time that the first studies on the function and activity of the human vestibular system, co-responsible for the perception of position and movement in space, were conducted.

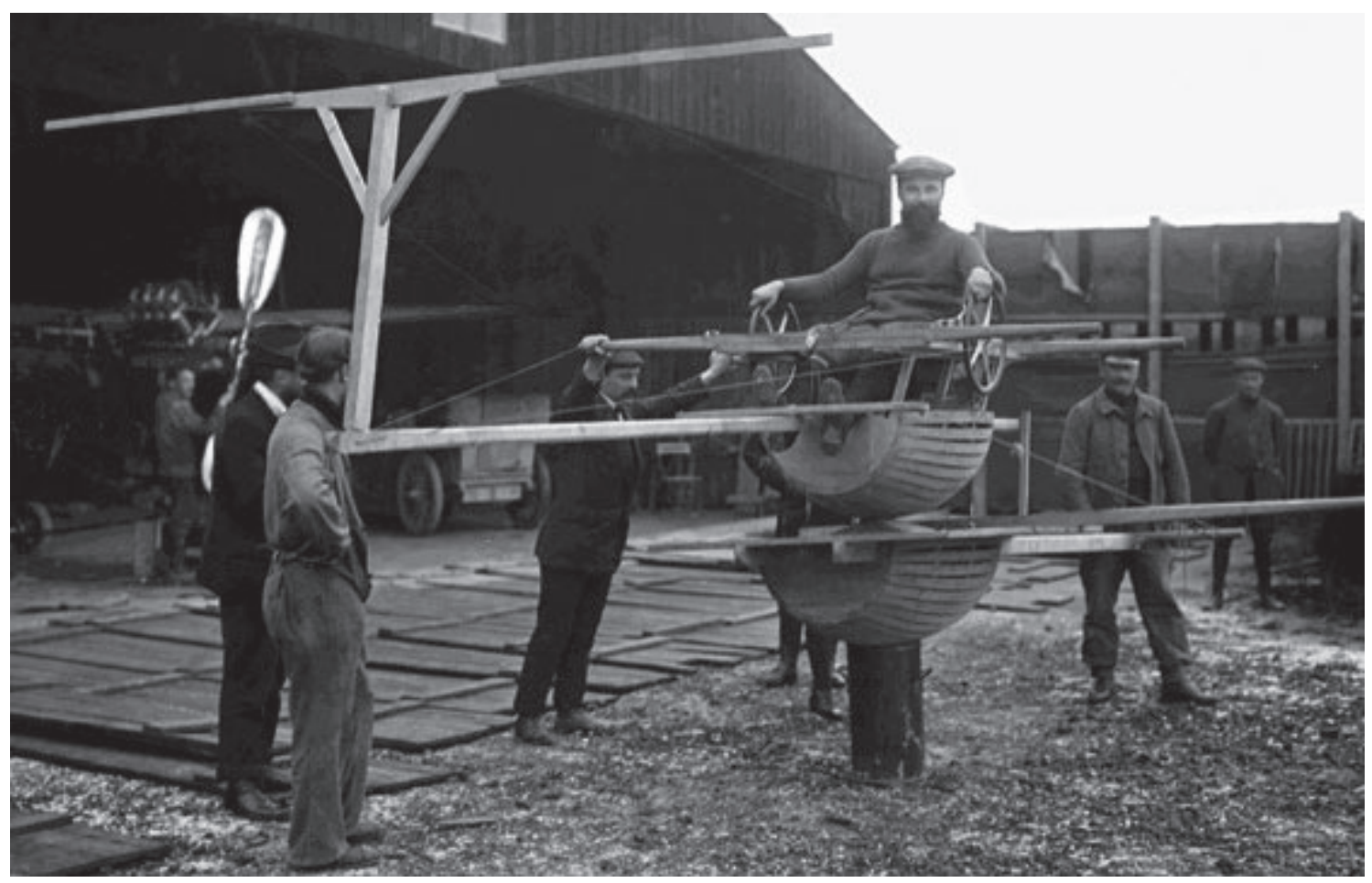

Fig. 1. Antoinette Trainer flight simulator [1]. 


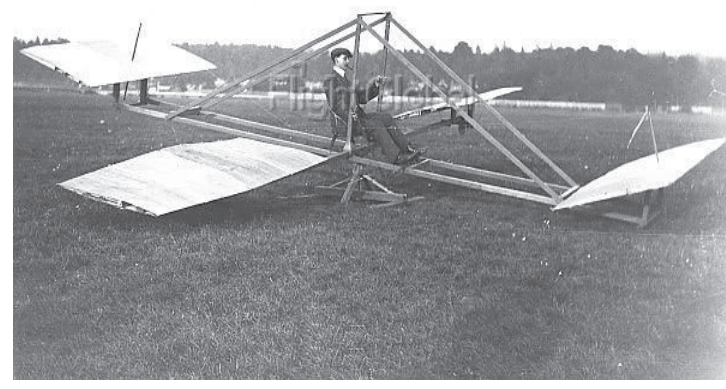

a)

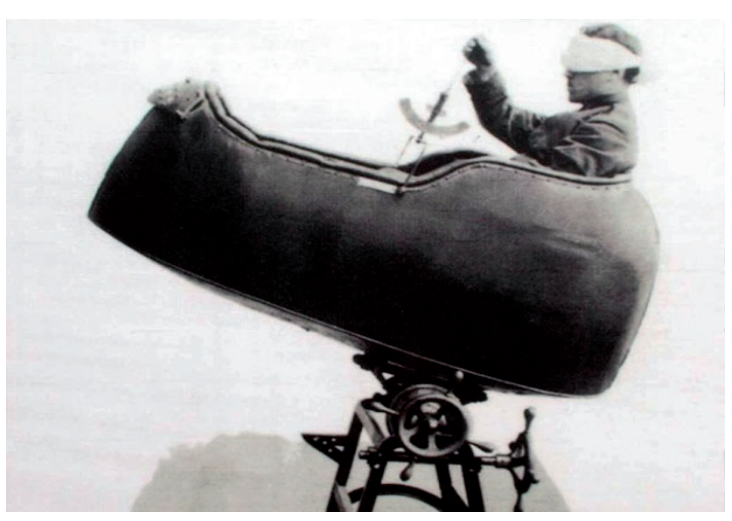

b)

Fig. 2. Flight simulators: a) Billing's Oscillator [2], b) Bleriot [3].

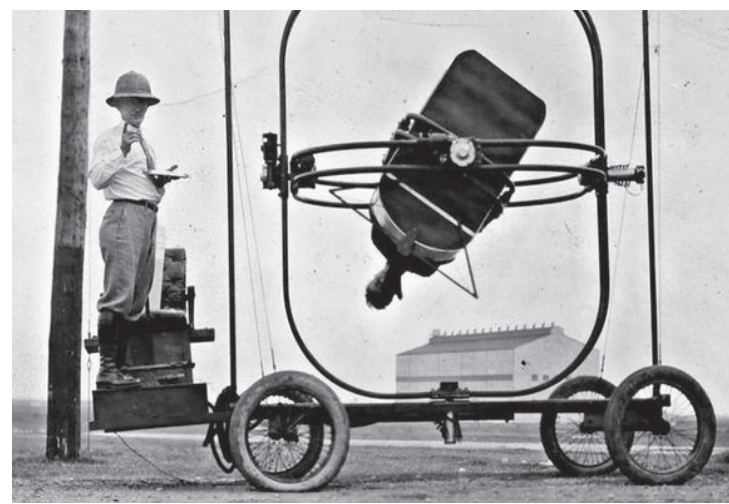

a)

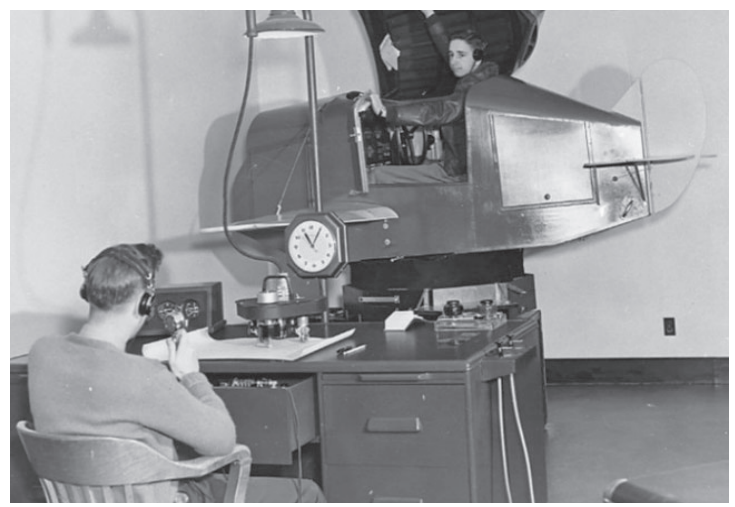

b)

Fig. 3. Simulators [4]: a) Ruggles Orientator, b) Link Trainer simulator.

The Billing's Oscillator (fig. 2a) developed by Eardley Billing, also comes from that period. It was a simple replica of an aircraft mounted on a plinth, which enabled simulation of basic movements during flight (pitch, roll and yaw angles).

By the time World War I began, anyone with an aircraft could have been a pilot. This has contributed to numerous accidents and losses in aviation that were not related to the activities of the enemy. Subsequent studies [3] have shown that out of all aviation accidents, as much as $90 \%$ were related to pilot error, $8 \%$ were related to aircraft malfunctions and only $2 \%$ were caused by shooting down. For this reason, the qualification of candidates for air duty was introduced. One of the first devices to train flying skills, and in particular to train and assess the physiological reactions of a pilot to stress caused by flying, was the Bleriot simulator designed at the University of Turin (fig. 2b). This simulator was able to perform roll and pitch movements that had to be recognized by the pilot candidate during a simulated flight with his eyes covered.

In 1917 the Ruggles Orientator training device was developed in the United States (fig. 3a) for learning and training to recover from an unusual aircraft attitudes. The main element of the simulator was a cabin with a pilot's seat, articulated in a set of rings on a wheeled platform [36]. Such a design allowed for any rotation of the cabin around three axes, with additional horizontal movement of the wheeled carrying platform. The movements were controlled by the instructor and the pilot by means of a rudder and bar, coupled in a system with an electric motor, responsible for generating the desired positions of the cabin. The pilot was able to move forward during the training, while feeling the impressions typical of basic maneuvers during flight.

The next qualitative leap in the flight simulation had not occurred until 1929, when American Edwin Link developed the Link Trainer simulator, also known as the Blue Box (fig. 3b). Adapting the concept of pneumatic bellows from his father's pipe organ factory, Edwin Link developed a structure enabling the generation of the cabin movement in pitch, roll and yaw channels [29]. The cabin movements were matched by trial and error method, independently for each control unit deflection. In addition to the motion system, which 
reacted to the rudder deflections, a new solution in Link Trainer was to equip the cockpit with flight instruments, coupled with the rudder system. The pilot, being in a darkened cabin, not only felt how the cabin reacted to the changes in rudder deflections, but most of all he could follow how the instrument indications change. Link Trainer was the first most successful flight simulator used until late 1950s.

\section{NEW DESIGNS OF MOTION SYSTEMS AND THEIR DEVELOPMENT}

Until the 1960s, major changes in flight simulation concerned subsystems other than the motion system. At that time, most flight simulators did not have a motion system, which was justified by the statement that modern pilots should not control the flight based on motion stimuli ('modern pilots should not fly by the seat of their pants') [28], considering information from the flight instruments as the most relevant during the flight. At that time it was considered that the lack of motion was partly compensated for by a system of loading the controls, providing a realistic feel for the forces occurring in flight. It was not until 1958 that Redifon company developed a full, motion system equipped simulator dedicated to the Comet IV aircraft. This simulator resembled flight simulators that are currently in operation. With the increased availability of flight test data and the increasing complexity of aircraft, analog computers have become a major limitation in the flight simulator system. The demand for increased fidelity and reliability of simulators was the reason for introducing digital computer techniques. However, digital signal processing has not improved the still low correlation of flight test data with the features of the simulator motion system. Moreover, strong visual stimuli provided by the wide field of view

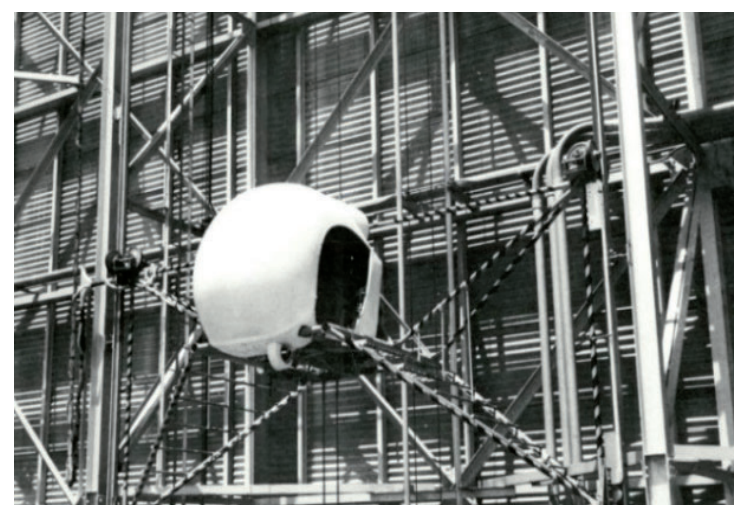

a) of the visual displayed system, in the absence of signals from the motion system, caused unintentional spatial disorientation in a pilot. At that time the most difficult to develop and the most expensive component of flight simulators was the motion generator.

In 1961, NASA Ames Research Center developed a flight simulator designed to simulate the vertical movements of an aircraft, helicopter or Vertical and/or Short Take-Off and Landing (V/ STOL) aircraft [17]. A device fixed to the outer wall of a building (fig. 4a) consisted of a two-seater cabin which, by means of a motorized winch, was moved in a vertical direction within \pm 50 feet at a speed of up to 22 feet per second and an acceleration of $\pm 1.5 \mathrm{~g}$ (g denotes the earth gravity acceleration).

Successive years of continuous development of aviation, supported by war experience, have made it possible to reach much higher flight altitudes and move at higher speeds. At that time, phenomena that had not occurred in flight before, or whose sources were not known yet [41], began to gain significance. An example of such a situation can be the G-induced Loss of Consciousness (G-LOC), occurring under flight conditions with large, often prolonged G-forces [44,45]. Numerous studies $[16,30,47-49]$ have shown that the pilot's body can be trained to prepare him for the flight conditions in which this type of hazard may occur. For this purpose, specialized simulators was developed, called centrifuges. In 1962, the engineers of NASA Ames Research Center developed five degrees of freedom (DoF) motion simulator - GPN-2000 (fig. 4b). The simulator combined in its design a centrifuge equipped with an arm, at the end of which a cabin was installed. The way the cab was controlled allowed to obtain angular changes of its position in relation to three axes. In addition, the cabin had the ability to move along

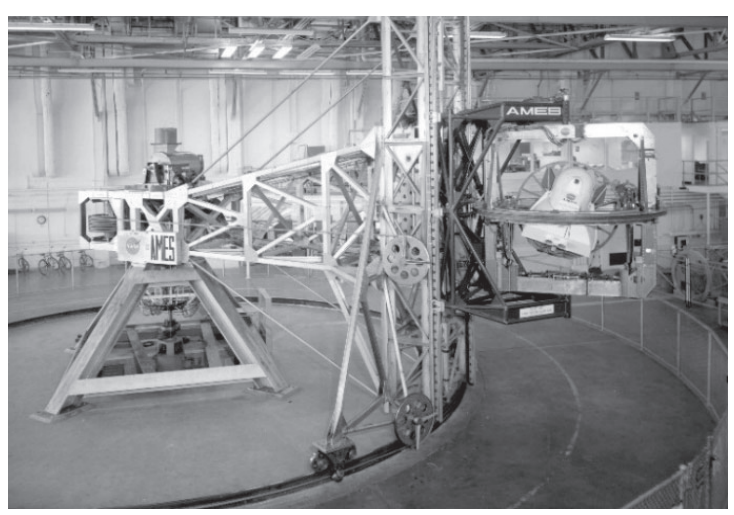

b)

Fig. 4. Flight simulator: (a) "height control test apparatus" [17], b) GPN-2000 [5]. 


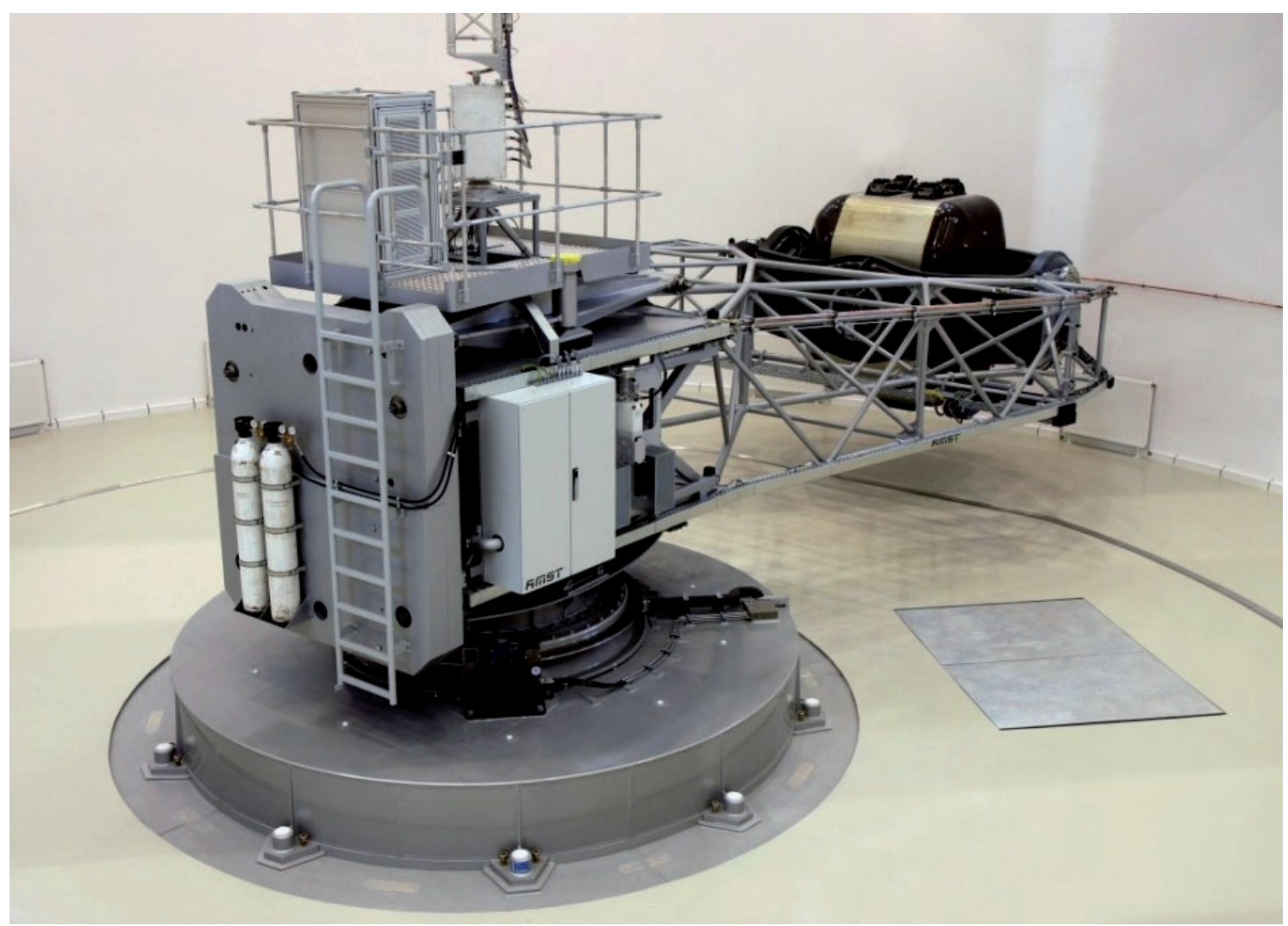

Fig. 5. The latest generation of the human-use centrifuge - a training flight simulator (WIML).

the vertical axis, limited to an offset of \pm 2 feet. In this way, the simulated cabin movements included three angular movements, one vertical translational and rotation of the arm in the horizontal plane.

In the latest generations of the human-use centrifuges (fig. 5) the way the gondola is fixed (with the aircraft cabin inside) enables its pitch and roll to be changed, providing mapping of linear accelerations with respect to three axes. Apart from many advantages of this type of simulator, there is, however, an inconvenience in the form of negative influence of cross-coupled angular acceleration stimulation (Coriolis stimuli), appearing when a pilot changes his/her head position during rotation of the centrifuge arm. In order to avoid the Coriolis effect, the pilot during centrifugation should maintain the unchanging position of the head, which is not natural when performing e.g. typical flight maneuvers [24].

Along with the rapid development of aviation to check the assumptions of newly designed aircraft, as well as spacecraft the first research simulators was built [41]. An example of such a simulator is the Flight Simulator for Advanced Aircraft (FSAA), built in 1969 and operated in NASA Ames Research Center Laboratory (fig. 6b) [12]. The simulator was originally designed for fixed-wing aircraft research, but was also used in rotary-wing (helicopter) models. Motion systems were usually the largest and most expensive elements of the simulator, expected to reproduce accelerations occurring in real flight more and more realistically. In order to meet the requirements of the V/STOL aircraft simulation, the first six DoF motion simulator was put into service at NASA in 1964 (fig. 6a). This simulator, in spite of the existing limitation in the cabin displacement (to a cube with a side length of $18 \mathrm{ft}$ ), demonstrated the importance of motion cues in flight simulation [13].

Almost simultaneously, Stewart [40] developed a motion system consisting of two platforms and six actuators, allowing for the imitation of motion with six DoF. An example of a flight simulator in which this type of motion platform is used is the lapetus simulator (fig. 7a), manufactured by ETC-PZL Aerospace Industries (Warsaw, Poland), installed as a training and research equipment at the Military Institute of Aviation Medicine (WIML) in Warsaw. This type of motion system, commonly referred to as the Stewart platform, has been recognized and appreciated by the motion simulation community. This platform has a relatively compact design, which allows motion a cabin with a large mass, reaching up to several tons [11]. The translational DoF include forward and backward movement - the so-called surge, 


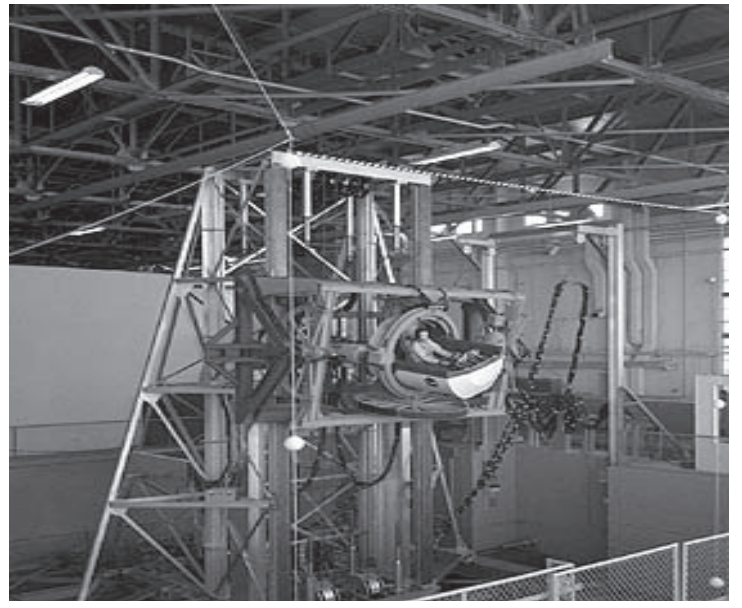

a)

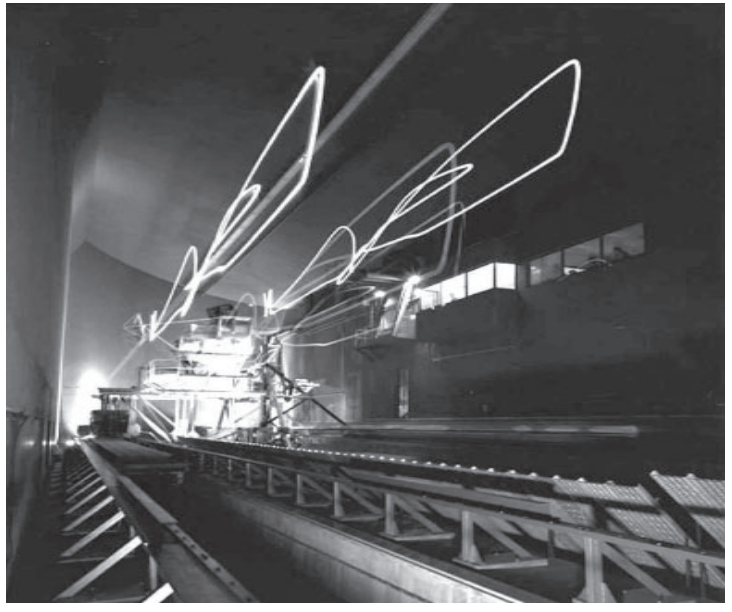

b)

Fig. 6. Motion simulator: a) with six degrees of freedom [6], b) FSAA [41].

sideways movement - the so-called sway, and up and down movement - the so-called heave. In the case of rotary motion, DoF include: roll, relative to the longitudinal horizontal axis, pitch, relative to the lateral horizontal axis, and yaw, relative to the vertical axis [37].

By the end of the 20th century, the Stewart platform was the most widespread six DoF motion system. The search for a more efficient motion platform to test all types of aircraft with very diverse flight dynamics led NASA Ames Research Center to develop the Vertical Motion Simulator (VMS) (fig. 7b). Its high mobility capabilities made it ideally suited for pilot-aircraft interaction studies. This simulator provided a realistic, in-flight substitute, environment used for the assessment of V/STOL aircraft, as well as for the training of

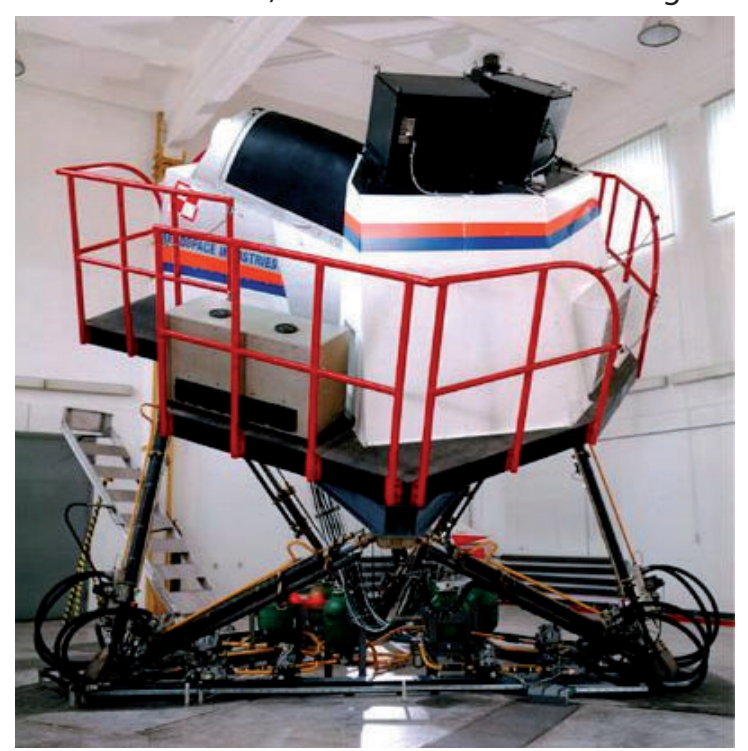

a) space shuttle pilots [14]. Reproducing the motion stimuli was achieved through the use of a special motion system with six DoF, for which, compared to the standard system, the range of vertical motion has been significantly increased - to $18.3 \mathrm{~m}$, with a maximum acceleration of $\pm 10 \mathrm{~m} / \mathrm{s}^{2}$. With the emergence of new generations of aircraft with high maneuverability, loss of spatial orientation has become one of the more frequent causes of aviation accidents. At that time, pilots were not familiarized with this phenomenon during flight training [41]. One of the most effective methods used to counteract the phenomenon of spatial disorientation include practical training in spatial disorientation simulators such as Gyro-IPT located at WIML (fig. 8a) or a simulator installed at the Air Force University in Dęblin (fig. 8b). Generating mo-

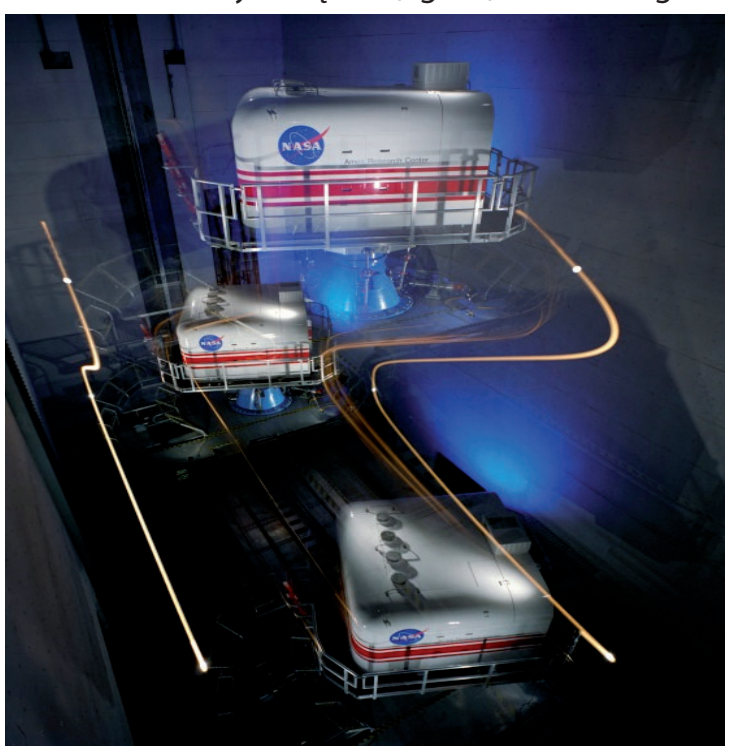

b)

Fig. 7. Flight simulators: a) Japetus (WIML) [42], b) VMS (NASA ARL) [7]. 


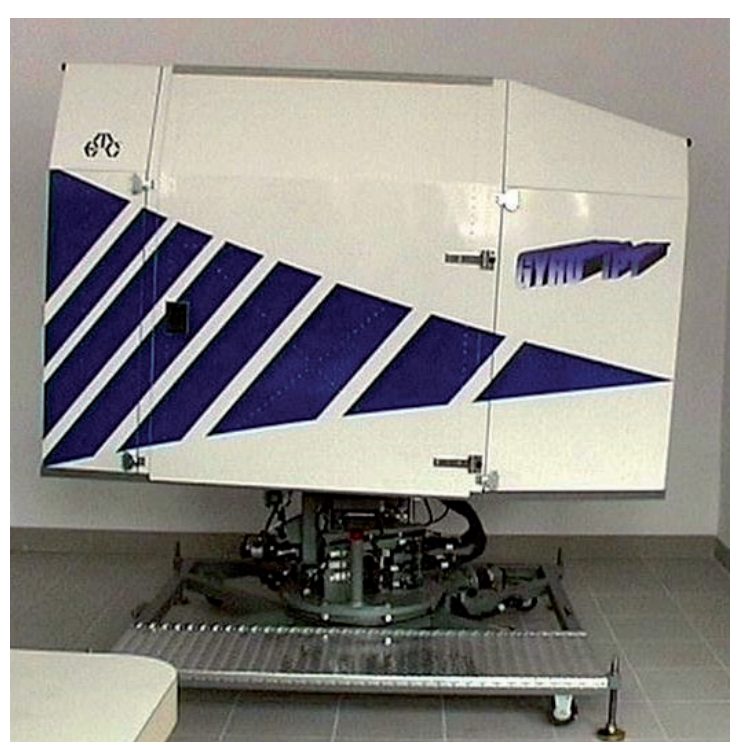

a)

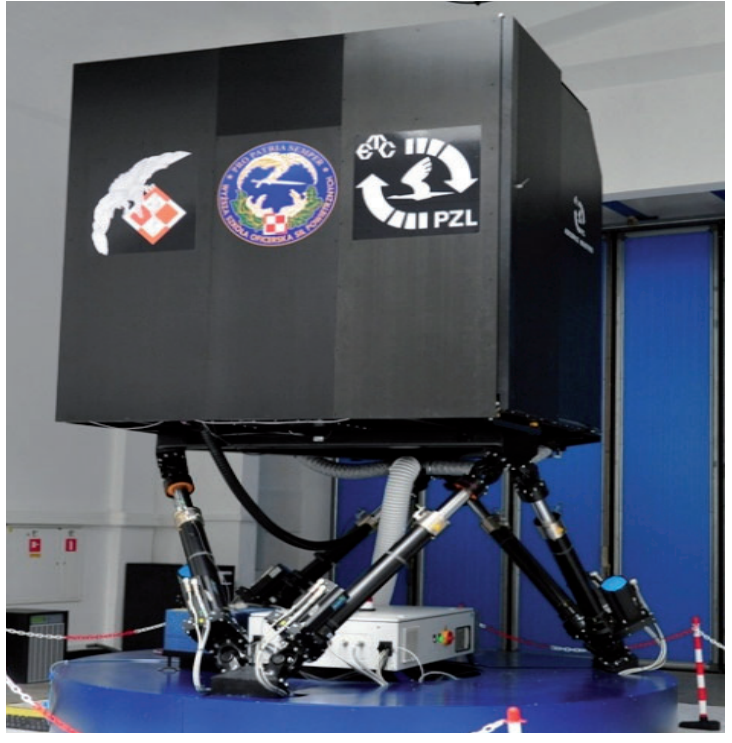

b)

Fig. 8. Spatial disorientation simulators: a) Gyro-IPT (WIML), b) WSOSP [8].

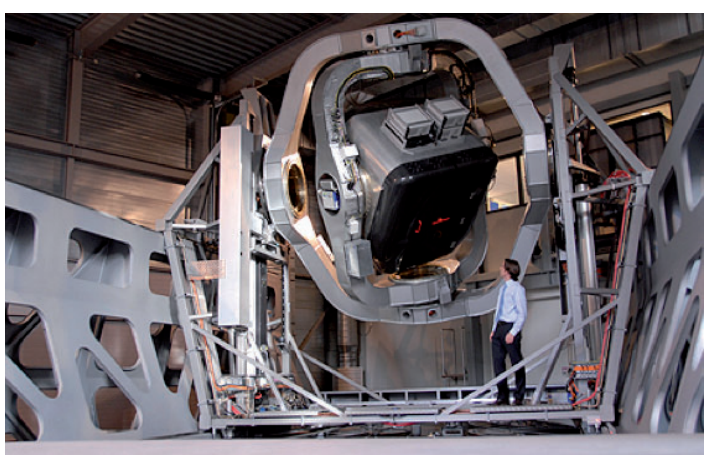

a)

Fig. 9. Flight simulator: a) Desdemona [9], b) DLR [10].

tion cues that cause spatial disorientation in flight are provided by appropriate kinematic properties of motion system.

The demand for greater motion fidelity affecting the pilot in real flight contributed to the development of complex structures of motion systems and their control systems [33]. Improvement in this fidelity is achieved by using multi-stage, cascading motion system connections. In this way, it is possible to increase the useful workspace of the motion system as well as the range of generated accelerations [11]. An example of such a solution is the Desdemona flight simulator developed by the AMST-Systemtechnik GmbH (Austria) (fig. 9a) $[22,46]$. This device is equipped with a motion system with six DoF ensuring full cabin rotation about three axes, its vertical movement within $\pm 1 \mathrm{~m}$ and horizontal movement along a rotating

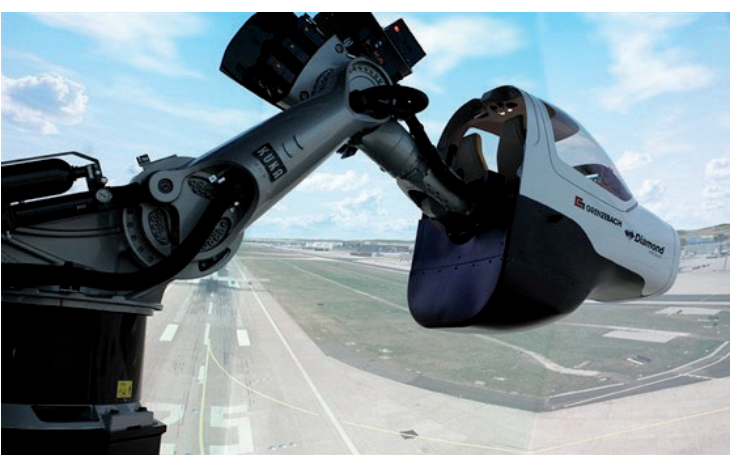

b)

arm within $\pm 4 \mathrm{~m}$. It has the capability to generate angular velocities up to $180 \% \mathrm{sec}$ with a maximum acceleration of $90 \% \mathrm{sec}^{2}$, and maintain prolonged linear acceleration up to $\pm 3 \mathrm{~g}$. Another example of a simulator with an advanced motion system is the DLR flight simulator (fig. 9b), which is mainly used for research purposes [43].

Today, flight simulators are used not only during the lifetime of an aircraft, but also in the research and development, helping to develop new aircraft designs and improve existing ones. They are also helpful in pilot assessment, reducing costs and risks associated with flight tests. However, the most commonly used flight simulators are flight simulation training devices (FSTD) designed for the training of pilots, flight crew and flight equipment service [41]. 


\section{THE NEED TO REPLICATE AIRCRAFT MOTION}

To date, despite numerous achievements in flight simulation, the simulator environment is not able to replace the actual aircraft flight. There is still a lot of discussion about the benefits of motion stimuli. There have been many prominent scientists in the group who were against the use of motion systems [31]. Caro [20] noted that the view negating the need for motion systems is not supported by evidence [34]. McCauley [31] was of a similar opinion, stating that the motion of the platform contributes to the precision of the pilot's actions and improves his/her performance. This applies especially to experienced pilots [27]. Although the author did not find any evidence for this, he pointed out that motion stimuli have a positive influence on flight training in unstable aircraft and when failures of systems responsible for maintaining stability may occur. Although the benefits of high motion fidelity have not been finally demonstrated, most experienced, qualified pilots prefer simulators with a motion platform [31]. According to Slob [38], the main reason for the need to use motion stimuli in simulation is to prevent the occurrence of simulator sickness (motion sickness). This simulator sickness is mainly the result of a lack of synchronization of visual stimuli with signals from the motion system. It is assumed that the motion cue delay should be lower or equal to the value of the visualization delay [38]. Burki-Cohen et al. [18] conducted a number of studies on the influence of flight simulator motion systems on the effectiveness of airline pilot training. Together with Sparko et al. [39] they demonstrated that during take-off and landing with high cognitive workload, the presence or absence of motion stimuli in the simulator does not significantly affect this efficiency. However, the authors of these studies concluded that higher dynamics and low flight altitude (e.g. rotary-wing aircraft flight) cause that pilots maintain their spatial orientation mainly based on signals from the vestibular system, rather than based on indications of flight instruments. It was proved by the studies $[23,32]$, in which the researchers confirmed that the presence of motion stimuli in a flight simulator affects the pilot's performance. On the other hand, there are numerous studies [19,21,25-27] indicating that increased realism in motion replication is not necessary for all elements of pilot training. This is justified in situations where the performance of certain tasks, for example communication with air traffic control and changes in autopilot settings, do not affect the pilot's behav- ior in the absence of motion stimuli. Nevertheless, the view that a full flight simulator is required to integrate all skills and pilot behavior during flight still remains $[25,35]$. In the course of disputes about the need to use physical motion stimulus in simulation, an attempt was made to classify the characteristics of motion systems in flight simulators [12]. The most important criteria were considered to be, the motion frequency translation band and response times (time delay of the system between the introduction of the control signal and the response of the actuators). Considering the large capabilities in flight simulator applications, the Federal Aviation Authority in the USA and the Joint Aviation Authority in Europe issued a motion system requirements specification in 1980 . Leaving these standards mostly unchanged for the next 15 years has practically stopped the development of motion systems. The current standards, which describe the requirements for flight simulator motion systems, are introduced by the European Aviation Safety Agency - certification specifications for areoplane and helicopter flight simulation training devices (CS-FSTD A/H). Similar qualification testing criteria for fixed-wing and rotary-wing aircraft simulators and training devices have been issued by the International Civil Aviation Organization in standard 9625 Issue 3.

\section{CONCLUSIONS}

Unfortunately, the motion system still remains one of the most expensive components of a simulator and one of the more troublesome in achieving high fidelity motion cueing. These limitations make the motion system an obligatory element of the simulator, only in the highest class of these devices, the so-called full flight simulators. Therefore, further development of motion systems seems to depend mainly on the costs of their production and operation and the quality of the replication physical motion stimuli in flight. An alternative to current motion systems are designs that combine low manufacturing cost with low fidelity. The increase in interest in such systems results mainly due to the availability of cheap devices for visual presentation of virtual reality.

It should be expected that also among the users of these motion systems, there will be "a hunger" for motion cueing fidelity. Perhaps this will be an impulse that will stimulate the development of motion systems and improve their fidelity. If with current technology it is possible to improve the motion cueing fidelity, there is a chance to increase interest in motion systems. Otherwise, it 
can lead to stagnation in their development. The current research on improving the motion cueing fidelity is focused mainly on:

- designing new motion system structures,

- creating new motion cueing algorithms to control motion systems,

- developing objective methods to assess the motion cueing fidelity.
While designing a new motion system is not a major problem, developing an appropriate algorithm to control this system is already quite a challenge. Human beings have numerous limitations in the perception of motion stimuli, both visual and vestibular. This knowledge is extremely useful for developing motion cueing algorithms and determining effective motion stimuli for specific device design.

\section{AUTHORS' DECLARATION:}

Study Design: Rafał Lewkowicz, Grzegorz Kowaleczko, Data Collection: Rafał Lewkowicz, Grzegorz Kowaleczko, Manuscript Preparation: Rafał Lewkowicz, Grzegorz Kowaleczko. The Authors declare that there is no conflict of interest.

\section{REFERENCES}

1. A photograph of the Antoinette Trainer flight simulator. Retrieved 1 Jun 2017 from: http://halldale.com/insidesnt/history-simulation-part-ii-early-days\#.VwtX1noXSFV

2. A photograph of the Billing Oscillator flight simulator. Retrieved 21 Feb 2018 from: https://www.mediastorehouse.com/ eardley-biling-oscillator/print/1570909.html

3. A photograph of the Bleriot flight simulator. Retrieved 21 Feb 2018 from: https://www.havkar.com/en/blog/view/first-aircraft-simulator/90

4. A photograph of the Ruggles Orientator. Retrieved 1 Jun 2017 from: http://jetpubs.com/news/go-boldly/

5. Photography of the GPN-2000 motion simulator with 5 degrees of freedom. Retrieved 1 Jun 2017 from: http://history.nasa. gov/SP-4302/ch3.3.htm

6. A photograph of a research motion simulator with six degrees of freedom. Retrieved 1 Jun 2017 from: http://history.nasa. gov/SP-3300/ch8.htm

7. A photograph of VMS at NASA Ames Research Laboratory. Retrieved 1 Jun 2017 from: http://ails.arc.nasa.gov/ails/printPreview.php?rid=11842

8. A photograph of the WSOSP spatial disorientation simulator. Retrieved 21 Feb 2018 from: http://4slsz.wp.mil.pl/pl/31_231. html

9. A photograph of the DESDEMONA flight simulator. Retrieved 1 Jun 2017 from: http://tmcporch.com/projects/mechatronics/ limits-motion-simulation/\#.VQ_p50GRZyF

10. A photograph of the DLR robotic flight simulator. Retrieved 1 Jun 2017 from: http://www.dlr.de/dlr/en/desktopdefault.aspx/ tabid-10084/161_read-9228/year-all/161_page-3/

11. Advani SK. The kinematic design of flight simulator motion-bases. MSc. thesis. Delft University of Technology. 1998.

12. AGARD. Dynamic characteristics of flight simulator motion systems. AGARD Advisory Report No. 144, AGARD, NATO, Neuilly sur Seine, France. 1979.

13. Aiken EW, Lebacqz J V., Chen RTN, Key DL. Rotorcraft handling - qualities design criteria development. NASA (Army Rotorcraft Technology. Volume 2: Materials and Structures, Propulsion and Drive Systems, Flight Dynamics and Control, and Acoustics. Washington. 1988.

14. Aponso BL, Beard SD, Schroeder JA. The NASA Ames vertical motion simulator - a facility engineered for realism. In: Royal Aeronautical Society Spring 2009 Flight Simulation Conference. London, UK. 2009; 3-4.

15. Baarspul M. A review of flight simulation techniques. Prog Aerosp Sci. 1990; 22(1):1-120.

16. Barański S, Markiewicz L, Wojtkowiak M, Sokołowski E. The role of physical training in increasing + Gz tolerance in the initial phase of aviation training. Physiologist. 1988; 51:24-27.

17. Bray RS. Vertical motion requirements for landing simulation. NASA-TM-X-62236. Moffett Field, CA. 1973. 
18. Bürki-Cohen J, Go TH. The effect of simulator motion cues on initial training of airline pilots. In: AIAA Modeling and Simulation Technologies Conference and Exhibit. San Francisco, CA. 2005; 516-527.

19. Bürki-Cohen J, Sparko AL, Go TH. Training value of a fixed-base flight simulator with a dynamic seat. AIAA 2007-6564. In: AIAA Modeling and Simulation Technologies Conference and Exhibit. South Carolina: AIAA, Inc. 2007; 1-21.

20. Caro PW. The relationship between flight simulator motion and training requirements. J Hum Factors Ergon Soc. 1979; 21(4):493-501.

21. Caro PW. Aircraft simulators and pilot training. Hum Factors. 1973; 15(6):502-509.

22. Groen EL, Trujillo M, Wentink M, Huhne R. Ground-based simulation of upset recovery in DESDEMONA: aspects of motion cueing and motion perception. In: AIAA Modeling and Simulation Technologies Conference and Exhibit. Honolulu, Hawaii. 2008; 1-3.

23. Hodge S, Perfect P, Padfield GD, White MD. Optimising the Vestibular Cues Available from a Short Stroke Hexapod Motion Platform. In: 67th American Helicopter Society Forum. Virginia Beach, VA. 2011.

24. Holly JE. Vestibular coriolis effect differences modeled with three-dimensional linear-angular interactions. J Vestib Res. 2004; 14(6):443-460.

25. Hosman RJAW. Are Criteria for Motion Cueing and Time Delays Possible? In: AIAA Modeling and Simulation Technologies Conference and Exhibit. Portland, Oregon: American Institute of Aeronautics and Astronautics. 1999.

26. Hosman RJAW, Hamman B, Lehman C, Pelchat Y, Schroeder JA. Summary of the panel discussion on motion cueing requirements. In: AIAA Modeling and Simulation Technologies Conference and Exhibit. Montreal, Quebec, Canada: American Institute of Aeronautics and Astronautics. 2001.

27. Jacobs RS. Simulator motion as a factor in flight simulator training effectiveness. 1975.

28. Koekebakker SH. Model based control of a flight simulator motion system. PhD. dissertation. Delft University of Technology. 2001.

29. Lansdaal M, Lewis L, Bezdek W. The history of commercial simulators and the boeing 777 systems integration lab. In: Collection of Technical Papers - AIAA Modeling and Simulation Technologies Conference. 2004; 594-607.

30. Markiewicz L, Wojtkowiak M, Steohni P. Wpływ ćwiczeń na symulatorze małych wartości przyspieszeń dośrodkowych na poziom tolerancji przyspieszenia. Med Lotnicza. 1985; 86:1-6.

31. McCauley ME. Do Army Helicopter Training Simulators Need Motion Bases ? Report 1176. United States Army Research Institute for the Behavioral and Social Sciences. Monterey, CA. 2006.

32. Mitchell DD, Key DL. Ground based simulation evaluation of the effects of IME delays and motion on rotorcraft handling qualities. Report No. AD-A256 921. Moffett Field, CA. 1992.

33. Moore R, Pope C, Foxlin E. Toward minimal latency simulation systems. In: AIAA Modeling and Simulation Technologies Conference and Exhibit (Vol 4176). Boston, MA: American Institute of Aeronautics and Astronautics. 1998.

34. Oosterveld WJ, Key DL, Bates GP, Bray RS, Walter S, Heinz F. Fidelity of simulation for pilot training. Neuilly sur Seine, France: NATO AGARD Advisory Report No. 159. 1980; 68.

35. Ray P. Quality flight simulation cueing - Why? In: AIAA Modeling and Simulation Technologies (MST) Conference. San Diego, CA: American Institute of Aeronautics and Astronautics. 1996.

36. Rolfe JM, Staples KJ. Flight simulation. Cambridge University Press. 1988; 300.

37. Sears A, Jacko JA. Human Computer Interaction: Fundamentals. 2nd ed. Sears A, Jacko JA, editors. Boca Raton, FL: CRC Press Taylor \& Francis Group. 2009; 352.

38. Slob JJ. State-of-the-Art driving simulators, a literature survey. DCT Report. Eindhoven. 2008.

39. Sparko AL, Bürki-cohen J, Go TH. Transfer of Training from a Full-Flight Simulator vs. a High Level Flight Training Device with a Dynamnic Seat. In: Proceedings of the AIAA Modeling and Simulation Technologies Conference and Exhibit (Vol 8218). Toronto, Canada: American Institute of Aeronautics and Astronautics. 2010; 1-38.

40. Stewart D. A platform with six degrees of freedom. In: Proceedings of the Institution of Mechanical Engineers 1847-1982 (vols 1-196). 1965; 371-86.

41. Szczepański C. Symulatory lotu w ostatnim 60-leciu. In: Sibilski K, editor. Mechanika w Lotnictwie ML-XV. Warszawa: Polskie Towarzystwo Mechaniki Teoretycznej i Stosowanej. 2012; 273-298.

42. Szczepański C. Symulatory jako środki kształcenia i szkolenia pilotów oraz nawigatorów dla Sił Powietrznych. In: Mechanika w Lotnictwie ML-XII. 2008; 1-18.

43. Teufel H, Nusseck HG, Beykirch K, Butler JS, Kerger M, Bülthoff HH. MPI motion simulator: development and analysis of a novel motion simulator. In: AIAA Modeling and Simulation Technologies Conference and Exhibit. Hilton Head, South Carolina. 2007; 1-11. 
44. Truszczyński O, Lewkowicz R, Wojtkowiak M, Biernacki MP. Reaction time in pilots during intervals of high sustained G. Aviat Sp Environ Med. 2014; 85(11):1114-20.

45. Truszczyński O, Wojtkowiak M, Lewkowicz R, Biernacki MP, Kowalczuk K. Reaction time in pilots at sustained acceleration of +4.5 Gz. Aviat Space Environ Med. 2013; 84(8):845-849.

46. Wentink M, Bles W, Hosman RJAW, Mayrhofer M. Design \& evaluation of spherical washout algorithm for Desdemona simulator. In: Proceedings of the AIAA Modeling and Simulation Technologies Conference and Exhibit. San Francisco, California. 2005.

47. Wojtkowiak M. Human centrifuge training of men with lowered +Gz acceleration tolerance. Physiologist. 1991; 34:80-82.

48. Wojtkowiak M, Biernacki MP. Comparison of the results of ATL and respiratory parameters before and after the anti-G training. Pol J Aviat Med Psychol. 2013; 19(1):5-12.

49. Wojtkowiak M, Truszczyński O, Kowalczuk K. Set of exercises increasing acceleration tolerance in the high performance aircraft pilots. Phys Educ Sport A Q J Phys Educ Phys Act Sci. 2006; 50:261-267.

Cite this article as: Lewkowicz R, Kowaleczko G. Development Of Motion Systems For Flight Simulators. Pol J Aviat Med Bioeng Psychol 2019; 25(1): 29-39. DOI: 10.13174/pjambp. 07.12.2020.03 